\title{
Arte contemporânea e ensino tecnológico: deslocamentos possíveis
}

\author{
Contemporary art and technological education: possible displacements
}

\author{
Arte contemporáneo y educación tecnológica: desplazamientos posibles
}

\author{
CARLA GIANE FONSECA DO AMARAL* \\ LUCIANA GRUPPELLI LOPONTE**
}

\begin{abstract}
$\longrightarrow \gg \longrightarrow$
RESUMO

Este artigo trata de algumas relações possíveis entre as áreas da arte, docência e ensino tecnológico, com o olhar dirigido à formação docente para o ensino técnico e profissionalizante. Apresentando considerações baseadas em uma pesquisa de Mestrado, e tendo aporte teórico em Nietzsche e Foucault, tratamos os movimentos provocados pela presença da arte, especialmente da arte contemporânea no contexto do ensino tecnológico como deslocamentos e os problematizamos em relação ao potencial formativo da experiência com arte contemporânea, a formação dos docentes que atuam na Educação Profissional e às concepções de arte presentes nesse sistema de ensino. Por fim, discorremos sobre as possibilidades de abertura à arte no ensino tecnológico e sobre potência da arte contemporânea para agenciar estratégias de formação continuada na EPT.
\end{abstract}

Palavras-chave: Arte. Docência. Ensino tecnológico. Deslocamentos.

\begin{abstract}
This article brings some possible relationship between art area, teaching and technological education, with emphasis on teacher' formation to technical education. Showing considerations based on a Master's research, and having theorethical suport in Nietzsche and Foucault, we treat the moviments caused by the presence of art, especially contemporary art in the context of technological education as displacements and we question this displacements relationship with the formation potential of experience whit contemporary art, teacher' formation of teachers who work in technological education and conceptions of art presentes in this educational system. Finally, we described about possibilities to opening to art at technological education and about the potential of contemporary art to develop strategies to continuing education on PTE.
\end{abstract}

Keywords: Art. Teaching. Technological education. Displacements.

\section{RESUMEN}

Este artículo trata de algunos vínculos posibles entre los ámbitos del arte, la enseñanza y la educación tecnológica, con la mirada dirigida a la formación de profesores para la enseñanza técnica y profesional. Con las consideraciones basadas en una investigación de maestría, y que tiene el apoyo teórico en Nietzsche y Foucault, en que tratamos a los movimientos causados por la presencia de arte, sobre todo contemporáneo en el contexto de la educación tecnológica como desplazamientos y cuestionamos sobre el potencial formativo de la experiencia con el arte contemporáneo, la formación de los docentes que trabajan en la Educación Professional y concepciones de arte presentes en este sistema de ensino. Por último, continuamos con las posibilidades de apertura del arte en la educación tecnológica y de poder del arte contemporáneo a negociar las estrategias de educación continua en la EPT.

Palabras clave: Arte. Enseñansa. Educación tecnológica. Desplazamientos.

\footnotetext{
* Mestre em Educação (UFRGS), professora do Instituto Federal Sul-rio-grandense Câmpus Sapucaia do Sul e doutoranda em Educação - Faced/UFRGS. E-mail: <carlagiamaral@gmail.com>.

**Doutora em Educação (UFRGS), professora do Programa de Pós-Graduação em Educação da Universidade Federal do Rio Grande do Sul, líder do ARTVERSA - Grupo de Estudo e Pesquisa em Arte e Docência (CNPq/UFRGS). E-mail: <luciana.arte@gmail.com>.
} 


\section{INTRODUÇÃO}

Arte. Docência. Ensino tecnológico. Palavras que representam temas que, por ora, parecem pertencer a campos de saber de relação quase improvável. Palavras que norteiam o pensamento que desenvolvemos nesse texto, onde colocamos essas áreas em interlocução a fim de produzir um pensamento que possa movimentar ideias a respeito das possíveis conexões entre esses temas.

Palavras, porém, não foram juntadas ao acaso. Essas áreas têm relação com pesquisas que desenvolvemos recentemente, que nos fazem acreditar no potencial da arte, especialmente da arte contemporânea, para subsidiar discussões que buscam abrir espaço para o estético na formação docente em qualquer área de conhecimento. Apresentamos nesse texto algumas considerações baseadas nos resultados de uma investigação ${ }^{1}$ que buscou aproximar os campos da arte e da formação docente, voltando o olhar para a formação dos professores que atuam na Educação Profissional e Tecnológica $^{2}$.

A opção por esse corpus de investigação advém da posição de uma das autoras desse texto como professora de arte em uma escola de ensino técnico e tecnológico ${ }^{3}$, atividade na qual utiliza como metodologia de ensino práticas de criação artística baseadas no estudo da arte contemporânea. A realização desses exercícios faz com que se extrapolem os limites das paredes das salas de aula e o espaço de uso comum da escola, como corredores, saguão e área externa, são ocupados com exposições dos trabalhos dos alunos ou servem como local de intervenção nas práticas artísticas criadas pelos mesmos (Figura 1).

Ainda que essas intervenções proporcionem experiências de aprendizagem prazerosas para os estudantes, sua realização fez com se percebesse que a presença da arte nesse ambiente provoca diferentes movimentos entre os quase 80 docentes de diversas áreas

\footnotetext{
1 Pesquisa desenvolvida no âmbito do Programa de Pós-graduação em Educação da Universidade Federal do Rio Grande do Sul, em nível de Mestrado, entre os anos de 2012 a 2014.

2 A Rede Federal de Educação Profissional e Tecnológica é uma rede de ensino da qual fazem parte instituições que se dedicam ao ensino profissional e tecnológico no Brasil: os Institutos Federais de Educação, Ciência e Tecnologia; os Centros Federais de Educação Tecnológica; as Escolas Técnicas Vinculadas às Universidades Federais e a Universidade Tecnológica Federal do Paraná. Todos são subdivididos em diversos campi, que de acordo com as necessidades de cada região, formam cidadãos para atuar em diversas áreas da economia.

3 Os cursos integrados oferecidos pelos Institutos Federais mesclam a formação profissionalizante com o ensino médio, sendo assim, todos os cursos integrados oferecidos nos IF's devem ter a Arte como parte de seu currículo.
}

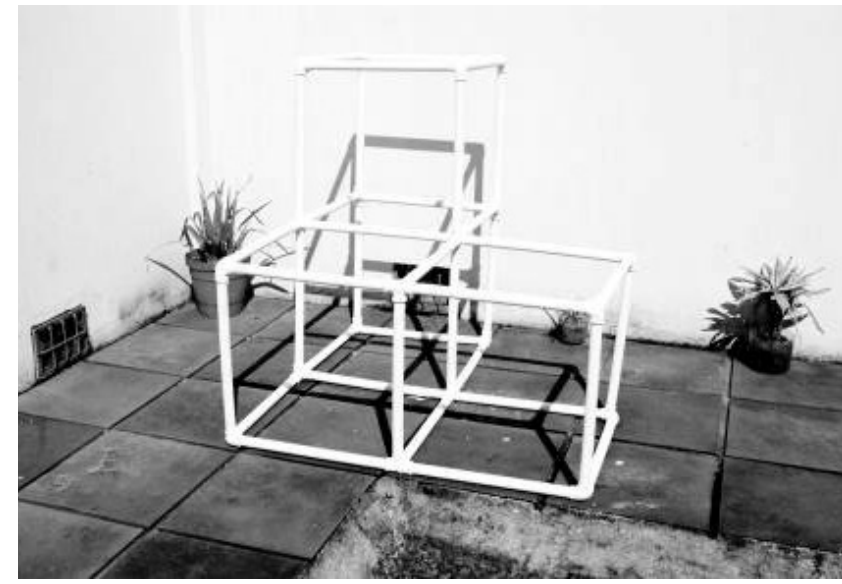

Fonte: Arquivo próprio.

Figura 1. Exercício realizado por aluno a partir do estudo da Arte Contemporânea. Instalação realizada em espaço de convivência interno. Ano de 2012.

de formação 4 que atuam no ensino tecnológico. Dúvidas a respeito do papel da arte no ensino profissionalizante e comentários dos professores sobre a necessidade da arte para a educação demonstravam diferentes e sutis formas de resistência à presença de práticas artísticas na escola, afloradas especialmente durante os momentos de exibição pública das atividades realizadas pelos estudantes, que provocam um encontro forçado de todos que circulam pelo câmpus com essas práticas. Evidências dessa resistência se apresentam constantemente: em conversas informais; debates em tempos de decisões gerenciais; discussões políticas ou que envolvem investimentos e atenção administrativa da instituição, entre outros.

Alguns docentes, porém, se mostram abertos às intervenções artísticas, compartilhando experiências com os colegas e estudantes. Alguns oferecem apoio na organização das atividades, incentivam alunos a tomar parte e demonstram reagir positivamente às práticas propostas.

Há também os professores que permanecem em silêncio. Os que passam pelos espaços modificados pela presença da arte e parecem não ter reação alguma. Será que a arte não os afeta? Será que pelo fato de terem sua formação em áreas distantes da arte ou o provável desconhecimento sobre arte faz com que saiam ilesos da relação com esses objetos? O fato de estarem ou não familiarizados com discussões pedagógicas poderia

\footnotetext{
4 As Diretrizes Curriculares Nacionais para a Educação Profissional Técnica de Nível Médio (Resolução nº 06, de 20 de setembro de 2012) permitem que docentes não licenciados atuem nesse sistema de ensino. Conforme dados levantados para a pesquisa, apenas $30 \%$ dos docentes que atuam no câmpus que deu base à investigação possuem licenciatura ou cursos de formação pedagógica, sendo em sua maioria bacharéis ou engenheiros em diferentes áreas, o que, de forma geral, é uma realidade bastante comum na educação profissional.
} 
implicar em uma maior ou menor abertura às práticas artísticas?

A partir da observação desses tensionamentos provocados pela presença de práticas artísticas em um ambiente dedicado ao ensino técnico e tecnológico ${ }^{5}$, questionamos que outros movimentos a presença da arte pode provocar entre esses docentes. Se a resistência parece ser grande, se parece haver algumas desconfianças ligadas à presença da arte em uma escola de ensino técnico, procuramos também estabelecer uma desconfiança: o que pode a arte na relação com esse campo de saber? Buscando colocar sob suspeita a crença de que a arte possui potencialidades apenas para os "especialistas", questionamos: que deslocamentos a arte, em especial a arte contemporânea, pode provocar para a docência no ensino tecnológico?

\section{FORMAÇÃO DOCENTE PARA A EDUCAÇÃO Profissional E TeCNOLÓgica}

Para problematizar as inquietações causadas pela presença da arte no ensino tecnológico, voltando o olhar para a docência nesse sistema de ensino é necessário dedicar algumas linhas à questão da formação docente para a $\mathrm{EPT}^{6}$. Tendo em vista que desenvolvimento econômico do Brasil e o crescimento da indústria durante o século XX tornaram o ensino técnico estratégico para o país, a formação dos profissionais para atuarem nessa rede foi diversas vezes discuta e revista. Silva (2012) lança um olhar sobre as especificidades desse tema, ao dizer que:

O trabalho docente na educação profissional tem particularidades e dilemas. O mais latente talvez seja a sempre presente dualidade estrutural do trabalho manual versus trabalho intelectual, que permeia as concepções de educação profissional presentes na história brasileira. (SILVA, 2012, p. 122).

\footnotetext{
5 Os conceitos de técnica e tecnologia são distintos. Técnica é associada basicamente à invenção e o uso de instrumentos, com formas que permitam satisfazer as necessidades da humanidade. Já a tecnologia é geralmente definida como a utilização de teorias e métodos científicos para resolverem-se problemas da técnica. A Rede Federal utiliza os termos como diferentes, relacionando o primeiro aos ensinos de nível técnico e profissionalizante e o segundo ao ensino superior. Nesse texto usaremos os termos ensino técnico e ensino tecnológico como referências ao mesmo sistema de ensino realizado nas instituições de Educação Profissional e Tecnológica, pois muitos docentes atuam em ambos os níveis de ensino, fazendo com que nossas reflexões perpassem esse sistema como um todo.

6 A sigla EPT será utilizada neste texto como abreviatura da expressão Educação Profissional e Tecnológica, pois assim vem sendo aplicada na literatura da área desde 2008, no início regulamentação da Rede Federal de Ensino Tecnológico no Brasil. Ela faz referência tanto à educação de nível médio integrada ao ensino técnico, à educação técnica no modo subsequente e à educação de nível superior, que se desenvolvem nas instituições pertencentes à Rede Federal de Ensino Tecnológico do Brasil.
}

Atualmente, a publicação oficial em vigor que traz aspectos em relação a esse tema é a Resolução no 06 , em 20 de setembro de 2012, que define as Diretrizes Curriculares Nacionais para a Educação Profissional Técnica de Nível Médio. Quanto à formação docente para a EPT, encontramos referências no Art. 40:

\begin{abstract}
Art. 40. A formação inicial para a docência na Educação Profissional Técnica de Nível Médio realiza-se em cursos de graduação e programas de licenciatura ou outras formas [...].

$\S 4^{\circ} \mathrm{A}$ formação inicial não esgota as possibilidades de qualificação profissional e desenvolvimento dos professores da Educação Profissional Técnica de Nível Médio, cabendo aos sistemas e às instituições de ensino a organização e viabilização de ações destinadas à formação continuada de professores. (BRASIL, 2012, p. 12).
\end{abstract}

Podemos perceber no enunciado do artigo a alusão a outros modelos de formação que não apenas a graduação e a licenciatura, deixando aberto o espaço para que profissionais não graduados possam atuar como docentes nesse sistema de ensino. A resolução permite inferir que para lecionar na EPT, o profissional docente precisa apenas saber ensinar a técnica com qualidade, sendo menos importantes os conhecimentos relativos à teoria e prática pedagógicas. No entanto, o parágrafo $4 \stackrel{0}{ }$ do artigo 40 , cita o fato da formação inicial não esgotar as possibilidades da qualificação e traz a formação continuada como um dever das instituições de ensino.

É importante destacar que nos últimos anos a Rede Federal de Educação Profissional e Tecnológica vem passando por um contexto de expansão que fez triplicar o número de escolas, além de trazer uma nova configuração para as instituições, que valorizam o ensino integrado e passam a investir também em pesquisa e atividades de extensão. A expansão vem sendo tratada como um desafio para toda a Rede Federal, especialmente para os docentes que nela atuam e que são referenciados como vetores pelos quais perpassa, de maneira determinante, a possibilidade de superação de seu modelo tradicional de ensino.

$\mathrm{Na}$ tentativa de colocar em suspensão o pensamento sobre as esferas da arte, docência e ensino tecnológico, apresentamos a seguir alguns desdobramentos em torno dessa questão, a fim de que não demore " [...] o tempo em que as forças artísticas e a sabedoria prática da vida se juntarão ao pensamento científico" (NIETZSCHE, 2001, p. 141, §113).

\section{DIALOGO COM AUTORES E ALGUMAS PROBLEMATIZAÇÕES}

Para pensar os movimentos provocados pela presença da arte relacionados à docência no ensino 
técnico, buscamos uma interlocução com autores tais como Nietzsche e Foucault, que possuem um modo de pensar que escapa da uniformização, e podem, por isso, mobilizar as contradições que aparecem na elaboração de um pensamento sobre esses temas.

Investimos, primeiramente, no pensamento do filósofo Friedrich Nietzsche $(2001,2011)$, pois ele confronta o apego às verdades incontestáveis, inventando outras maneiras de interpretar convicções naturalizadas. As ideias de Nietzsche nos auxiliam a refletir sobre a relação entre a arte e a educação profissional, dado que em seus escritos nos convida continuamente à experimentação e ao questionamento dos valores estabelecidos.

Destacamos principalmente a aproximação que o filósofo estabelece entre arte e vida, que tratamos como potência para o pensamento sobre a docência na EPT. Ele diz que "Como fenômeno estético a existência ainda nos é suportável, e por meio da arte nos são dados olhos e mãos e, sobretudo, boa consciência, para poder fazer de nós mesmos um tal fenômeno" (NIETZSCHE, 2011, p.132, §107). Sua valorização dos impulsos estéticos como elementos que podem provocar a criação de diferentes possibilidades de existência leva-nos a acreditar que a arte pode provocar acontecimentos que modificam os processos de formação e têm uma potência que favorece espaços de encontro onde algo novo pode acontecer. Segundo o filósofo, a arte pode nos colocar uma "[...] interrogação sobre o valor da existência" (NIETZSCHE, 2001$, p. $14, \S 1)$, que pode ter um papel essencial na educação, pois proporciona um exercício constante de reencontro com a natureza contraditória da vida.

O filósofo Michel Foucault, herdeiro das ideias e escritos de Nietzsche, torna-se importante nessa discussão por evocar continuamente esse pensamento que não deixa de se reinventar, que não deixa de buscar a diferença. No capítulo denominado Modificações, de História da Sexualidade II, Foucault (1998) conta sobre como suas pesquisas o levaram a um deslocamento, fazendo-o afastar-se de seu projeto inicial de estudo e reorganizálo a fim de melhor cumprir sua tarefa. Foucault não deixa esses descaminhos teóricos nos bastidores, ele os evidencia em seus estudos, tratando essa mudança como parte essencial do seu pensamento filosófico:

[...] esforçar-se, começar e recomeçar, experimentar, enganar-se, retomar tudo de cima a baixo e ainda encontrar os meios de hesitar a cada passo, àqueles para quem, em suma, trabalhar mantendo-se em reserva e inquietação equivale a demissão, pois bem, é evidente que não somos do mesmo planeta (FOUCAULT, 1998, p. 12).

O mesmo propósito de modificar o pensamento também aparece em AArqueologia do Saber (FOUCAULT,
2008). Quando o autor é questionado a respeito de uma possível mudança de opinião em seus próximos livros, ele evidencia o quanto é importante não permanecermos atrelados a um pensamento estático:

[...] Você pensa que eu teria tanta dificuldade e tanto prazer em escrever, que eu teria me obstinado nisso, cabeça baixa, se não me preparasse - com as mãos um pouco febris - o labirinto onde me aventurar, deslocar meu propósito, abrir-lhe subterrâneos, enterrá-lo longe dele mesmo, encontrar desvios que resumem e deformam o seu percurso, onde me perder e aparecer, finalmente, diante dos olhos que eu não terei mais que encontrar? (FOUCAULT, 2008, p. 20).

Tomamos emprestada de Foucault a noção de deslocamento como potência para essa discussão, porque assim como o autor, desejamos efetuar um desvio das convicções iniciais sobre a relação entre a arte e a EPT, encontrando o que pode ser caracterizado como um descaminho na relação entre a docência na educação profissionalizante e a arte. Entendemos os movimentos que a arte, em especial a arte contemporânea, pode provocar nesse campo da educação como deslocamentos e os tratamos como possibilidade de alteração de alguns pressupostos que vêm se consolidando ao longo dos anos no ensino técnico, como: separação entre racional e emocional; valorização de procedimentos instrumentais para resolver problemas pedagógicos; menor importância às áreas ligadas às ciências humanas; desvalorização da arte na formação dos estudantes; entre outros.

$\mathrm{Na}$ perspectiva dos pensamentos desses autores, acreditamos que a docência no ensino profissional pode ser movimentada a partir de um elemento que causa estranhamento a esse sistema de ensino - a arte - e discutimos o alcance desta como parte dos processos de formação docente na EPT.

\section{ESTÉTICA, EXPERIÊNCIA ESTÉTICA E ARTE CONTEMPORÂNEA}

Baseamos essa discussão na ideia de que a arte pode desencadear experiências estéticas que possuem uma capacidade formativa capaz de alterar diferentes processos de formação, entre eles a formação docente. Mas de que estética ou de que experiências estéticas estamos falando?

Ao longo dos anos a palavra estética vem sendo utilizada a partir de diversos entendimentos, sendo comum o conceito de estética como estudo do belo, tendo no objeto de arte sua base de estudo. Passando pelas ideias de arte como imitação, beleza, decoração, expressão e outras, o fundamento da estética estava, até meados do século XX, nos objetos de arte e era a partir desses objetos que as reflexões sobre a natureza do belo se estabeleciam. 
Porém, a história da arte e suas sucessivas rupturas forjam mudanças no entendimento de arte, que trazem diferenças também à história da estética.

Essas mutações no conceito de arte continuam acontecendo nos dias atuais quando novas atividades artísticas colocam em cheque a validade da estética enquanto teoria dedicada aos objetos artísticos. Atualmente, a arte contemporânea faz do contexto parte fundamental na prática da arte e a progressiva eliminação das barreiras entre a arte e cotidiano afetam o entendimento de estética como ciência fundamentada exclusivamente nos objetos. Isso se dá porque a arte contemporânea não trabalha apenas com objetos concretos, mas principalmente a partir de conceitos e atitudes, nos fazendo pensar que "A arte é um encontro contínuo e reflexivo com o mundo em que a obra de arte, longe de ser o ponto final desse processo, age como iniciador e ponto central da subsequente investigação do significado" (ARCHER, 2001, p. 236).

Nesse contexto, a estética passa a estar situada no olhar de quem vê, na maneira como cada indivíduo percebe e frui ${ }^{7}$ os objetos artísticos. Assim, a questão da experiência vem à tona:

Ao contrário de perguntar o que é arte ou se isso é uma obra de arte, vale tomar em questão a experiência de algum objeto, situação, acontecimento ou processo naquilo que ele tem em termos de potencial artístico, ou seja, naquilo que o configura como um acontecimento estético (PEREIRA, 2011, p. 113).

Experiências mais cotidianas como os exercícios escolares que citamos na introdução desse texto, a visão de uma paisagem diferente ou o simples fato de se atravessar um túnel grafitado na agitação da cidade, também podem se configurar em experiências estéticas, quando possuírem características que os tornem capazes de desviar o sujeito do campo de racionalidade que antes o circunscrevia (PEREIRA, 2011) e provocar outras capacidades éticas.

Não estando mais atrelada exclusivamente aos objetos de arte, essa capacidade de criar novas experiências subjetivas torna-se agora, uma das vertentes no estudo da estética, pois "A estética não existe enquanto teoria da arte, mas sim enquanto forma de experiência, um modo de visibilidade e um regime de interpretação. A experiência estética vai muito além da esfera da arte" (RANCIÈRE, 2009, p. 18).

Assim, sustentamos essa discussão nas artes visuais contemporâneas, pois, embora o contato com a arte

\footnotetext{
7 Fruição artística significa, nesse contexto, a apreciação significativa da arte e do universo a ela relacionado, que pode se configurar em experiência estética.
}

não garanta a experiência estética, produções artísticas possuem a capacidade de colocar em movimento os planos da sensibilidade, emoções e o corpóreo (HERMANN, 2010). Notadamente a arte contemporânea, com suas imprevisíveis manifestações e fusão de materiais, linguagens e tecnologias, apresenta uma nova forma de tratar dos temas atuais.

A diversidade cultural; o processo de pluralização de valores e crenças; efemeridade dos hábitos e flexibilidade de condutas são algumas das características de nosso mundo polissêmico que a arte contemporânea tem sido capaz de abranger. São essas particularidades que os artistas contemporâneos trazem para suas produções, pois nos ensina Nietzsche (2011) que os artistas “[...] se acham à espreita, para descobrir coisas assim e transportá-las para o domínio da arte" (NIETZSCHE, 2011, p. 114, § 85).

Isso é o que podemos encontrar nas obras da artista chinesa Cao Fei "Utopia de quem?" e "O que você está fazendo aí?" expostas na 9 ${ }^{\text {a }}$ Bienal do Mercosul $^{8}$ em Porto Alegre. As obras são resultado de uma aproximação entre a artista e empregados de uma fábrica de lâmpadas da China e busca mostrar as pessoas que estão implicadas na fabricação de produtos. "Utopia de quem?" é um vídeo divido em partes: na primeira é mostrado o dia-a-dia da fábrica com os trabalhadores em suas funções e rotinas. $\mathrm{Na}$ segunda parte, vários trabalhadores aparecem no vídeo, em um contexto diferente que estão acostumados: como por exemplo, uma bailarina que dança pelos setores da fábrica enquanto outros trabalham.

Além do vídeo, outra parte do trabalho chamado "O que você está fazendo aí?" traz a perspectiva dos trabalhadores de uma forma diferente: uma árvore seca é suporte para peças de roupa dos funcionários, que no lugar das etiquetas traz cartas dos donos das peças escritas por eles mesmos ${ }^{9}$. As cartas contam como eles foram trabalhar na fábrica, como são sua rotina e seus sentimentos a respeito do trabalho, demonstrando que, por trás de cada operário, há uma história de vida (Figura 2).

As discussões levantadas a partir da obra de Cao Fei colocam diante de nós a capacidade da formação pela experiência estética, o que pode ser aproveitado no campo da formação docente, pois proporciona uma abertura dialética dos sujeitos para novos modos de compreensão de si mesmo e do outro. Hermann (2005), diz que “[...] a experiência estética permite novos acessos para a

\footnotetext{
8 A 9a Bienal do Mercosul, que aconteceu em Porto Alegre de 13 de setembro a 10 de novembro de 2013, consistiu em um momento de reflexão a partir do diálogo entre arte, ciência e tecnologia. O título da mostra Se o clima for favorável propunha uma articulação entre temas como descoberta, invenção, sustentabilidade, mudanças climáticas, e desenvolvimento social, entre outros.

9 Informações do site <http://sociolgossa.blogspot.com.br>. Acesso em: 12 de out. 2014.
} 


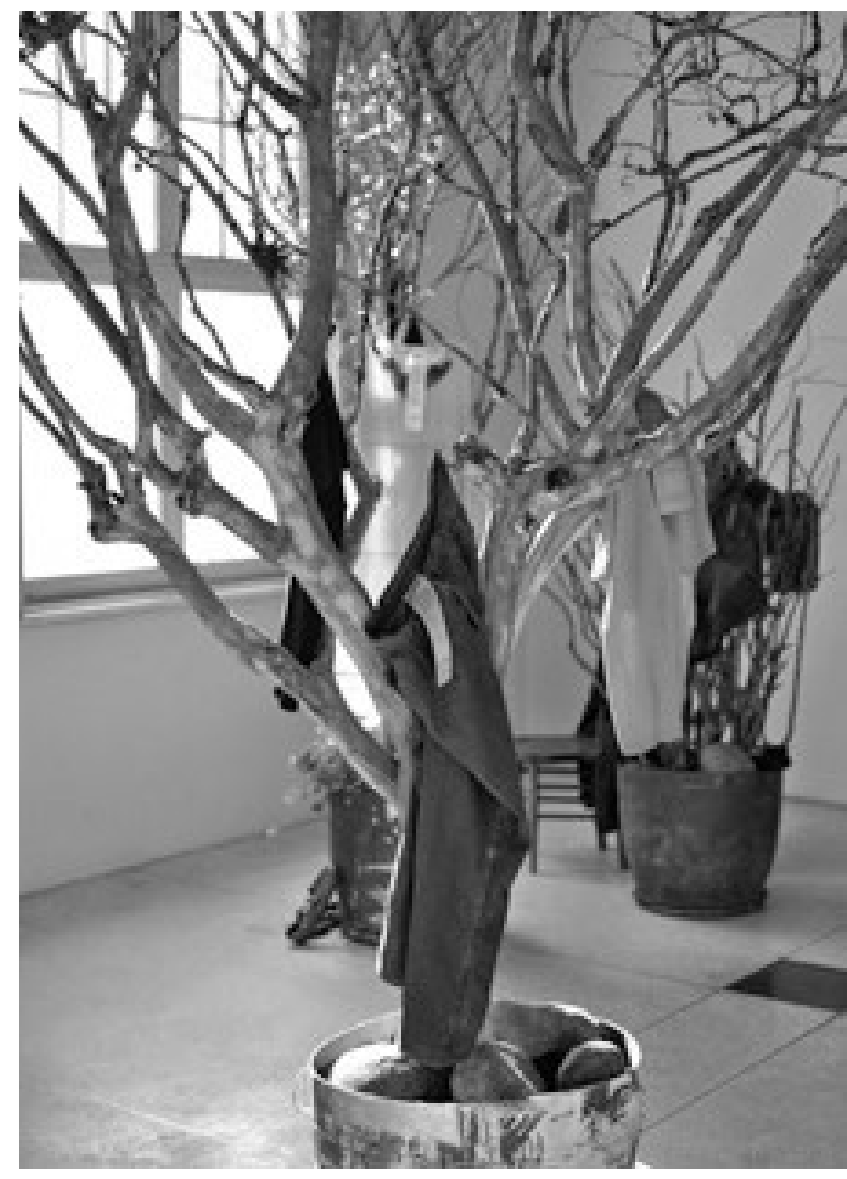

Fonte: Arquivo próprio.

Figura 2. FEI, Cao - O que você está fazendo aí? - Utopia de Quem.

educação pensar o sentido de sua ação, especialmente porque traz o frêmito que transborda o domínio conceitual e racionalizado" (HERMANN, 2005, p. 16). Assim, entendemos que a arte contemporânea, com suas provocações, pode deslocar o pensamento dos docentes do ensino tecnológico para desviar de suas convicções estabelecidas e legitimadas, provocando algum deslocamento nos valores estabelecidos nesse sistema de ensino, e, quem sabe, produzir descontinuidades que tragam algo novo para o pensamento sobre a docência na educação profissionalizante.

\section{ARTE E DESLOCAMENTOS PARA A DOCÊNCIA}

O desejo de investigar os deslocamentos que a experiência com arte provoca entre os docentes do ensino tecnológico fez com que elaborássemos estratégias metodológicas para produção de dados que permitissem evocar as ambiências na relação entre as áreas da arte, docência e ensino tecnológico. Essas estratégias foram: envio de questionários por e-mail aos docentes da escola referida na introdução desse texto, durante exibição pública de intervenções realizadas por alunos em espaços de uso comum do campus (Figura 1); exibição de vídeos de caráter artístico produzidos por alunos no saguão da escola, com aplicação de questionários aos professores; e ainda, entrevistas com docentes de diferentes áreas de formação, permeadas por imagens de arte contemporânea.

Essas estratégias metodológicas proporcionaram momentos de aproximação entre a arte contemporânea e os docentes da EPT que subsidiaram a pesquisa a partir da qual desenvolvemos esse texto. Os dados produzidos por elas permitiram que pudéssemos observar diferentes deslocamentos provocados pela arte entre os docentes do ensino tecnológico. Deslocamentos esses que reafirmam a potência da arte, especialmente da arte contemporânea, para impulsionar estratégias de formação continuada docente na educação profissional.

\section{FORMAÇÃO DOS DOCENTES DA EPT E RELAÇÕES COM A ARTE}

Os movimentos provocados pela arte na escola de ensino técnico citada nesse texto faziam-nos suspeitar, inicialmente, que as reações de alguns professores às práticas artísticas tinham relação com a maior ou menor familiaridade destes com discussões pedagógicas em sua formação, especialmente as desenvolvidas durante a licenciatura. Assim, buscamos, a partir das estratégias metodológicas citadas acima, entender a relação da formação inicial dos docentes com os movimentos que a arte provoca entre eles, investigando a afinidade dos professores de diversas formações com a área da arte.

De acordo com Pereira (2011) "[...] entendemos que experimentada é a pessoa que, justamente por ter tido as experiências que teve, está aberta a novas e inéditas experiências." (PEREIRA, 2011, p. 116). Sendo assim, entendemos que a abertura ou a frequência com que os docentes costumam, ou não, se aproximar da arte em sua vida, pode ter relação com os movimentos que a arte provoca nesse sistema de ensino. Na contramão de nossas suspeitas iniciais, os dados produzidos na investigação indicam que não há relação intrínseca entre a formação inicial dos docentes da EPT pesquisados e sua proximidade com a arte na vida cotidiana, pois tanto professores licenciados quanto não licenciados relataram diferentes posições pessoais em relação à fruição da arte: alguns disseram já ter tido mais contato com arte em outros momentos da vida, outros afirmaram não achar significativa a proximidade com a arte; sendo que a maioria relatou não ter o costume de procurar a fruição artística.

Destacamos ainda que alguns professores da EPT fazem uma analogia do conceito de arte à ideia de entretenimento, estando no campo do supérfluo, que pode 
ser deixado em segundo plano. Nietzsche (2001), porém, nos alerta para o risco de considerarmos a arte como entretenimento, dizendo que a arte não deve ser deixada apenas no nível da distração, pois é tarefa suprema e atividade metafísica da vida. Para ele, os homens se encontram em perigo caso "[...] não estejam em condições de reconhecer na arte mais do que um divertido acessório, do que um tintinar de guizos que se pode muito bem dispensar ante a seriedade da existência" (NIETZSCHE, 2001, p. 26, § 1).

Outros dados produzidos na pesquisa deixam escapar a constatação que docentes sem licenciatura e de formação tecnicista também são dispostos e abertos às práticas artísticas públicas na instituição. Essa constatação nos fez notar o que a formação inicial em licenciatura não é determinante para a maior ou menor abertura às atividades artísticas na escola. Por outro lado, a mesma pesquisa trouxe indícios de que as experiências pessoais dos docentes com a arte na vida cotidiana é que podem ser consideradas vetores importantes na abertura dos docentes da EPT à arte na escola.

Assim, reafirmamos a potência da arte para além da recreação, pois acreditamos que, especialmente as produções artísticas contemporâneas possuem um papel essencial na formação dos sujeitos, por proporcionar um exercício constante de reencontro com a natureza contraditória da vida.

\section{CONCEPÇÕES DE ARTE PRESENTES NA EPT E DESLOCAMENTOS}

Pressupondo que algumas desconfianças com relação à presença da arte no ensino tecnológico tivessem origem nas concepções de arte dos docentes que nela atuam, investigamos essas concepções relacionando-as aos diferentes movimentos provocados pelas intervenções artísticas na escola.

Enquanto produto da imaginação humana, o termo "arte" não é sempre tomado com a mesma acepção, destacando-se os entendimentos de arte como imitação, beleza, sublime, comunicação e outras. Essas diferentes percepções a respeito de arte estão baseadas em convenções e critérios que advém, muitas vezes, do ensino de arte realizado na educação básica. Para muitos de nós, a escola básica foi a primeira instância de aproximação com o universo artístico, o que pode ter determinado os entendimentos a respeito de arte que nos marcam, pois o que conforma os olhares que se lança para a arte, muitas vezes, é o que é limitado pela nossa experiência escolar.

Considerando a pesquisa realizada entre os docentes da EPT, percebemos que é marcante entre esses professores o entendimento de arte como expressão de sentimentos e emoções, identificada como uma prática portadora de características que podem sensibilizar as pessoas, transmitir alegria e bons sentimentos. Essa concepção de arte pode ser compreendida no contexto da fruição gratuita "[...] em que se pensa a arte como contrabalanço da racionalidade científica" (FAVARETTO, 2010, p. 231), associada à revelação de sentimentos do mundo interior. Imanol Agirre (2005) indica diferentes possibilidades de se entender o ensino de arte e as atividades artísticas que podem ser relacionadas às concepções de arte que identificamos durante a pesquisa. Sobre o entendimento de arte como expressão, o autor diz que " [...] a aquisição da capacidade de obter experiências estéticas se basearia no cultivo da dimensão emocional do ser humano e no livre desenvolvimento das capacidades criadoras inatas do indivíduo" (AGIRRE, 2005, p. 219 - tradução nossa).

Outra concepção de arte marcante na investigação é a que entende a arte como comunicação, ou seja, uma técnica que torna possível capturar a mensagem que está sendo dita e entender o que o artista quis dizer. Isso nos permite afirmar que muitos professores da EPT entendem a arte como uma manifestação portadora de mensagens que necessitam de uma explicação para serem compreendidas. A arte é entendida como um tipo de linguagem não verbal, que teria a capacidade de auxiliar no desenvolvimento do pensamento crítico, através de informações que podem ou não estar claras na obra através dos elementos da linguagem visual e que precisam ser decodificadas para que se atenda ao objetivo da comunicação. Sobre essa concepção Agirre diz:

O objetivo prioritário dessa orientação é ter o que denominam como "alfabetização visual", ou seja, a competência na "emissão" e, sobretudo, "leitura" de suas mensagens visuais, já que a comunicação visual implica que o receptor seja capaz de perceber e interpretar - decodificar - adequadamente as mensagens elaboradas pelo criador (AGIRRE, 2005, p. 256 - tradução nossa).

Aparece também na produção de dados a ideia de arte como uma manifestação que tem criatividade $\mathrm{em}$ $s i$, como se a criatividade fosse uma característica que $o$ artista conseguiu passar para a obra ou como se a arte pudesse despertar a criatividade. Esse entendimento de que a criatividade está na arte e que é necessária para a educação converteu-se, segundo Agirre (2005) em uma utopia educativa, sendo evocada sem cessar nos discursos pedagógicos que clamam por um professor criativo para encontrar recursos novos que solucionem os problemas de sala de aula. De acordo com o autor:

[...] a questão da criatividade parece ser o porto onde todo mundo encontra amparo, a panaceia que deveria solucionar todos os nossos problemas escolares. Está 
generalizado o uso excessivo e indiscriminado do termo, que está dando como resultado uma grande confusão conceitual e exegética (AGIRRE, 2005, p. 173 - tradução nossa).

Essa compreensão liga-se à ideia de que a arte tem diversas colaborações a dar para a educação, entre elas: aplicação de técnicas artísticas como recursos que podem ser aproveitadas em diferentes disciplinas ou o uso da arte para amenizar conteúdos difíceis. Apesar dos muitos avanços reconhecidos no ensino de arte no Brasil, a partir dos movimentos em prol da sua renovação, não se pode dizer que essas concepções foram deixadas de lado, pois, de forma ou outra, acabam por afetar as ideias a respeito de ensino da arte que perpassam a EPT, onde, em muitos momentos a arte ainda é considerada como uma atividade extracurricular ou acessória.

Entendemos que a ligação da arte com os aspectos da expressão, comunicação e criatividade marcantes nas falas dos docentes muitas vezes não encontram eco nas intervenções propostas pelos alunos na escola, que são na maioria das vezes baseadas em conceitos da arte contemporânea. Esses exercícios exploram o inusitado, a partir de materiais, técnicas e suportes diferentes que exigem também um observador disposto a interagir de forma diferente (Figura 3).

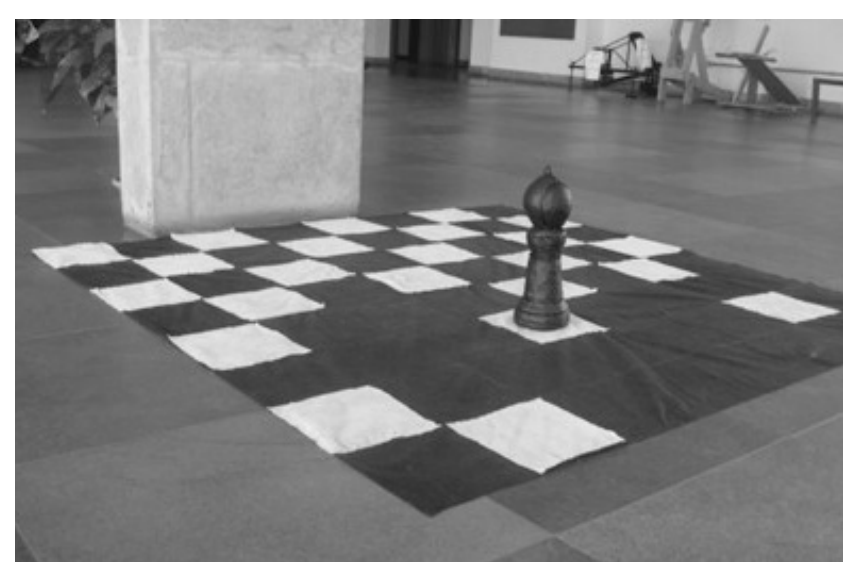

Fonte: Arquivo das autoras.

Figura 3. Exercício realizado por alunos a partir do estudo de Arte Contemporânea. Instalação realizada no saguão de entrada da escola. Ano de 2012.

A arte contemporânea, assim como os exercícios artísticos na escola, "[...] provoca, instiga e estimula nossos sentidos, descondicionando-os, isto é, retirandoos da ordem pré-estabelecida e sugerindo ampliadas possibilidades de viver e de se organizar no mundo" (CANTON, 2009, p. 12). É possível que, quando os docentes da EPT não conseguem entender a mensagem nas propostas artísticas, quando não se sentem tocados por sentimentos ou quando não encontram pinturas e trabalhos alegres entre as atividades dos estudantes, seja para eles difícil relacionar essas práticas com suas concepções de arte e talvez por isso, em alguns momentos prefiram ser indiferentes ou desconfiar do que está exposto.

Em paralelo a essas concepções tradicionais, os dados da investigação indicaram também que alguns docentes apresentam entendimentos de arte mais amplos, em compasso com a noção contemporânea de arte, considerando a multiplicidade comum do campo artístico. Em muitos momentos da análise de dados percebemos vozes de docentes que compartilham do conceito de arte com potencial reflexivo e como modificação de sentidos, próxima dos questionamentos artísticos contemporâneos.

Ao demonstrarem que compreendem o potencial ético da arte, esses professores parecem também estar dispostos a se colocar em uma posição de abertura às intervenções artísticas, o que pode provocar a quebra de sentidos e a construção de novos, abrindo uma fissura para uma visão diferente com relação à presença da arte nesse sistema de ensino. Há relatos onde professores da EPT dizem que, ao ter contato com a arte, não permanecem a mesma pessoa, se tornam reflexivos, pensando sobre a obra que tiveram a oportunidade de fruir ou sobre como essa obra pode interferir em sua maneira de compreender o mundo.

Juntamente a essa visão mais ampla do conceito de arte, os dados indicam também que a frequência e a presença marcante da arte na instituição de EPT pesquisada têm produzido deslocamentos na escola, no sentido de que a comunidade escolar está se interessando mais por essas atividades. As produções artísticas, marginalizadas em algumas situações, se estabelecem entre lutas e disputas e pontuam sua constância na formação dos estudantes, despertando olhares mais abertos também por parte de docentes de outras áreas do conhecimento. Parece que essa maior disponibilidade à fruição artística na instituição vem aumentando na medida em que as intervenções se tornam mais frequentes.

Identificamos esse deslocamento na forma de perceber a arte na instituição com o que diz Foucault (1998) a respeito da atividade filosófica, que para ele é o trabalho crítico do pensamento sobre o próprio pensamento, que consiste "[...] em tentar saber de que maneira e até onde seria possível pensar diferentemente em vez de legitimar o que já se sabe.” (FOUCAULT, 1998, p. 13). Quando percebemos que essa instituição de EPT deixa de legitimar apenas a racionalidade técnica como modelo educacional e se abre ao potencial da estética na formação, entendemos que a presença da arte parece estar agenciando estratégias que modificam as formas de pensar a respeito de educação nesse espaço, sinalizando possíveis deslocamentos a partir da arte. 
Hermann (2010) diz que "A arte contém um elemento que ultrapassa o domínio da reflexão, o que nos põe diante do estranho, provoca novos questionamentos, solicita uma compreensão para além daquilo que é habitual" (HERMANN, 2010, p. 53). Esses questionamentos, aliados ao potencial reflexivo da arte e à frequência das atividades, parece ser o que, nessa instituição, vem deslocando a costumeira resistência ou rejeição em direção a uma maior abertura às práticas artísticas.

\section{A POTÊNCIA DA ARTE PARA A FORMAÇÃo CONTINUADA DOCENTE NA EPT}

Acreditando que a formação docente é um processo contínuo, que não chega nunca a ter um fim determinado, entendemos que o fato dos professores da EPT serem parte de um processo educacional constante, os torna partícipes de uma formação docente que não para de acontecer, pois se atualiza cotidianamente, das mais diferentes formas: na relação com alunos, colegas, espaços e atividades; assim como nos anseios, expectativas e particularidades fazem parte do ambiente e do processo educativo.

Por isso, o reconhecimento de diferentes movimentos que a presença da arte provoca entre docentes de diversas áreas que atuam no ensino profissional nos fez problematizar, especialmente durante as entrevistas, o potencial dessa para a formação continuada docente na EPT. Em paralelo com algumas questões da entrevista, apresentamos imagens de obras de arte cuja iconografia $^{10}$ trazia referências ao campo da educação, visando provocar reflexões a respeito das práticas pedagógicas.

Algumas das imagens apresentadas fazem parte da série fotográfica Classroom Portraits, do fotógrafo inglês Julian Germain, que apresenta diferentes alunos, escolas e grupos culturais no espaço da sala de aula, questionando as práticas educativas contemporâneas e as divisões sociais. Ao aproximar essas imagens de arte contemporânea dos docentes, percebemos durante a pesquisa, que professores que já haviam relatado não ter familiaridade com a arte em sua vida cotidiana, apresentaram certa dificuldade de relacionar as imagens aos seus ambientes de ensino, vendo-as primeiramente como algo distante de sua profissão. As análises que eles fizeram das imagens se detiveram na descrição que estavam vendo e na busca por semelhanças físicas com o ambiente educacional no qual estão inseridos.

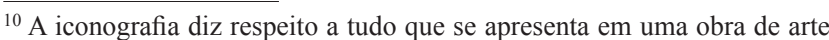
em termos de descrição visual, ou seja, é a descrição dos elementos que a obra apresenta.
}

Como o planejamento aberto da pesquisa permitia autonomia, em alguns momentos os sujeitos passaram a ser estimulados com perguntas e comentários, a partir dos quais puderam pensar mais a respeito dos possíveis questionamentos que as imagens traziam. Sua atenção foi, em algumas situações, deslocada para o conteúdo das imagens, os objetos, as expressões, as posições, sendo realizada uma espécie de mediação que dispusesse os olhares dos pesquisados a serem mais cuidadosos, mais aguçados e abertos.

Nos momentos em que foi feita essa mediação, percebemos que o olhar dos docentes se tornou mais atento à pluralidade de sentidos que podem ser encontrados nas imagens da arte. Os dados produzidos na investigação permitem perceber que, ao serem estimulados a interagir com a arte contemporânea e seu emaranhando de possibilidades, os professores passaram a refletir sobre educação, a partir das imagens que estavam vendo. A partir disso, acreditamos que a arte é capaz de instaurar um pensamento sobre educação entre esses docentes, se apresentando como potencial para problematizar momentos de formação continuada no âmbito da educação profissional, pois:
Nessa direção, a leitura de mundo, provocada pela desestabilização da fruição da obra artística, dá-se quando o sujeito, forçado pela necessidade de organizar a experiência caótica que a arte lhe proporcionou, refor- mula a sua percepção, conferindo novos sentidos ao vivenciado (AMORIM; CASTANHO, 2008, p. 1175).

Mesmo que a educação profissional seja um espaço em que frequentemente $o$ ato de aprender seja relacionado à repetição de uma técnica com perfeição e onde predominam referências de uma educação fragmentada e racionalista, acreditamos que a experiência com arte, com sua potência para nos colocar diante daquilo que nos interpela, desloca os sujeitos em direção ao seu caráter formativo, indicando que "[...] algo vem à luz como resultado do enfrentamento do sujeito com a obra de arte" (HERMANN, 2010, p. 53).

Consideramos que a produção dessas sutis mudanças na forma como se relacionam com as reproduções de obras de arte surgidas durante as entrevistas são indícios marcantes de que a arte contemporânea - com suas provocações para o exercício de pensamento - é uma potência que pode ser explorada nos processos de formação continuada docente na EPT.

Os dados produzidos na investigação permitem inferir que a educação técnica e profissionalizante pode, a partir da aproximação com a arte contemporânea, favorecer-se da pluralidade de sentidos que essa experiência promove. Não sendo necessário abrir mão do seu objetivo de desenvolver capacidades produtivas para o mercado de 
trabalho, entendemos que problematizar a docência na EPT a partir de um viés com o qual esses profissionais não estejam acostumados, que lhes seja surpreendente, pode significar a adoção de postura mais flexível diante da docência.

A partir da proximidade dos docentes com o campo estético, apostamos em uma atitude mais errante na educação tecnológica, que escapa à sobriedade e à teimosia em perseguir parâmetros predefinidos. Uma docência que, ao contrário disso, inventa novas formas de se relacionar com o mundo, indo além da racionalidade instituída nesse sistema de ensino, pois entende que “[...] toda vida repousa sobre a aparência, a arte, a ilusão, a óptica, a necessidade do perspectivístico e do erro" (NIETZSCHE, 2001, p. 19, § 5).

\section{CONSIDERAÇÕES FINAIS}

No percurso desse texto buscamos relacionar áreas que, inicialmente, pareciam pertencer a campos distintos: arte, docência e ensino tecnológico; e tentamos refletir sobre os possíveis deslocamentos que a arte provoca em um sistema de ensino que apresenta resistências ao campo artístico. Ao finalizar essa escrita, reafirmamos a relevância da experiência com arte para problematizar a educação tecnológica e sugerimos que a arte contemporânea pode mobilizar deslocamentos nesse sistema de ensino, a partir de sua potência formativa.

Embora a educação profissional, em alguns momentos, ainda ambicione por um tipo de educação permanente onde é possível se atrelar a modelos, apostamos no hibridismo da aproximação entre arte, docência e ensino tecnológico, pois acreditamos que essa relação pode fazer com que os envolvidos aprendam a questionar suas certezas, indo em busca de uma realidade diversa para a educação. Desejamos que a multiplicidade dessas reflexões possa "se equilibrar sobre tênues cordas e possibilidades e em dançar até mesmo à beira de abismos" (NIETZSCHE, 2001, p. 241, § 347) configurando saberes ainda não pensados nesse campo de contingências.

\section{REFERÊNCIAS}

AGIRRE, Imanol. Teorías e Prácticas em Educación Artística: Ideas para uma revisión pragmatista de la experiencia estética. Barcelona: Octaedro/EUB, 2005.

AMORIM, Verussi; CASTANHO, Maria Eugênia. Por uma educação estética na formação universitária de docentes. Campinas: Educação e Sociedade, v. 29, n. 105, p. 1167-1184, set./dez. 2008.

ARCHER, Michel. Arte Contemporânea: uma história concisa. São Paulo: Martins Fontes, 2001.

BRASIL. Resolução n. 6, de 20 de setembro de 2012. Define Diretrizes Curriculares Nacionais para a Educação Profissional Técnica de Nível Médio. Diário Oficial da República Federativa do Brasil, Brasília, 21 de setembro de 2012, Seção 1, p. 22.

CANTON, Kátia. Do moderno ao contemporâneo. São Paulo: Martins Fontes, 2009.

FAVARETTO, Celso. Arte contemporânea e educação. Revista Iberoamericana de Educación, n. 53, p. 225-235, 2010.

FOUCAULT, Michel. A arqueologia do saber. Rio de Janeiro: Forense Universitária, 2008.

FOUCAULT, Michel. História da Sexualidade 2: o uso dos prazeres. Rio de Janeiro: Graal, 1998.

HERMANN, Nadja. Autocriação e horizonte comum: ensaios sobre educação ético-estética. Ijuí: Editora Unijuí, 2010.

HERMANN, Nadja. Ética e estética: a relação quase esquecida. Porto Alegre: EDIPUCRS, 2005.

NIETZSCHE, Friedrich. A Gaia Ciência. São Paulo: Companhia das Letras, 2011.

NIETZSCHE, Friedrich. O nascimento da tragédia ou helenismo e pessimismo. São Paulo: Companhia das Letras. 2001.

PEREIRA, Marcos Villela. Contribuições para entender a Experiência Estética. Revista Lusófona de Educação, América do Norte, n. 18, p. 111-123, dez. 2011.

RANCIÈRE, Jacques. A partilha do sensível. São Paulo: EXO Experimental, 2009.

SILVA, Carla Odete Balestro da. Docência no PROEJA: pensando a formação continuada. In: MARASCHIN, Mariglei S. et al. Formação docente, acesso e permanência na educação profissional: estudos sobre o PROEJA. Pelotas: Editora da UFPEL, 2012.

Submetido em 13/11/2015

Aprovado em 30/03/2016 